\title{
Characterising copper-based metals in Britain in the first millennium AD: a preliminary quantification of metal flow and recycling
}

\author{
A.M. Pollard, Peter Bray, Chris Gosden, Andrew Wilson \\ \& Helena Hamerow*
}

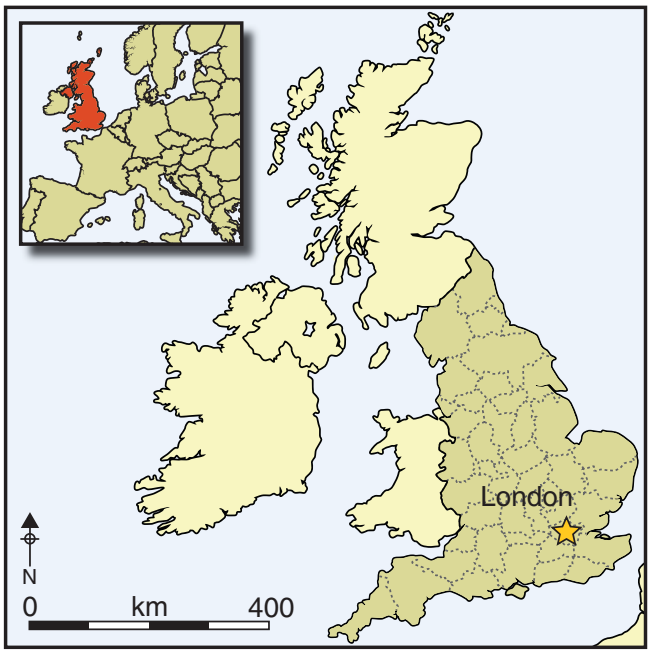

For many years, archaeologists and archaeometallurgists have suggested that recycled copper might have constituted a significant component of the metal in circulation in Britain during the first millennium $A D$. They have generally failed, however, to suggest a way of observing and quantifying this phenomenon. Here the authors propose a new methodology to rectify this. A large new database of chemical analyses of British copper alloys dating from the late Iron Age to the early medieval period demonstrates the potential of their approach; it shows that significant and measureable changes occur in metal circulation at the beginning of the first century $A D$ and in the early Saxon period.

Keywords: Britain, first millennium AD, archaeometallurgy, copper alloys, recycling metal, life histories

In an essay studying the evidence for Bronze Age metalworking in the Middle Volga of Russia, Peterson (2009: 194) wrote:

Although discussions of ancient Eurasian metalwork have frequently assumed a direct correlation between the element composition of the metal in objects and their sources, practices such as alloying and recycling can alter the element profiles of copper and bronze to the point that the origin of the materials found in individual pieces is hopelessly obscured. Recycling also has significant socio-economic implications, as it changes the production cycle from one that is initiated with mining to another in which metalworkers may operate more independently from miners and smelters. 
This position is in stark contrast to the more optimistic views about provenancing ancient metal artefacts that came to dominate archaeometallurgy for a large part of the previous century. It would appear that, in most quarters, this optimism regarding the suitability of trace elements, and subsequently lead isotopes, for determining the provenance of copper $(\mathrm{Cu})$ has now given way to a realisation that these enquiries are potentially complicated, and perhaps even futile at times when recycling and re-alloying are common. We present here a new method of examining the chemical data that we believe has the potential to reveal the extent of such practices and to point towards a way of partially disentangling such information. It is based on the concept of a dynamic flow of metal in circulation over both space and time, which manifests itself as a particular set of objects with particular forms at any given time, rather than taking a static view of both form and composition as fixed properties. The composition of this flow of metal is influenced by the coming and going of new sources of metal, but it is also affected by the recycling and re-alloying of metal objects already in circulation. Thus, the chemical and isotopic analyses of a set of objects are merely a 'snapshot' of the composition of the metal in circulation at that time. We see chemical composition as an indicator of the 'life history' of the metal from which a particular object is made. We do not initially attach importance to the exact values of the composition of an object. Instead, we initially use the presence or absence of trace elements to classify the category of metal in circulation, and only then use the distribution of particular elements within and between these categories to document this history more closely.

To illustrate this methodology, we present a very broad preliminary interpretation of the copper in circulation in Britain from the late Iron Age to the beginning of the medieval period, with a particular focus on the transition from the end of Roman occupation into the Anglo-Saxon period. To do this, we have used four large datasets covering the period: Caple (1986), Blades (1995), Dungworth (1995) and Bayley and Butcher (2004). These datasets were selected because of the large number of multi-period analyses that they present (c. 5340 samples), and because they appear to be internally and mutually consistent. A more detailed discussion of the data is given in the online supplementary material. For the purposes of this preliminary overview, we have focused on a restricted time period, from the early Iron Age to the end of the late Saxon period (AD 1066), although most of the data fall into the first millennium $\mathrm{AD}$. We consider two primary aspects of the data-the varying proportions of alloying metals - tin $(\mathrm{Sn})$, lead $(\mathrm{Pb})$ and zinc $(\mathrm{Zn})$ used over time, and, for Blades's data only, the trace elements - arsenic (As), antimony ( $\mathrm{Sb})$, nickel $(\mathrm{Ni})$ and gold $(\mathrm{Ag})$ - present in the copper.

\section{Classification of alloys}

Traditionally, archaeological copper alloy types are classified by the amounts of each alloying element (zinc, tin and lead) present, displayed either as a triangular diagram (plotting only the normalised values of these three elements), or as a binary plot (usually tin $v s$ zinc), with the term 'leaded' being added if the lead concentration exceeds a specified value. For example, Table 1 shows the definitions specified by Bayley and Butcher (2004: 14), based on a combination of zinc: tin ratios and absolute values for tin or zinc. Using this, a 'brass' has to have more than $8 \%$ zinc and also four times more zinc than tin. If, in addition, it

(C) Antiquity Publications Ltd, 2015 
Table 1. Copper alloy classifications according to Bayley and Butcher (2004: 14).

\begin{tabular}{lcc}
\hline & Zinc: tin ratio & Absolute values \\
\hline Brass & $\mathrm{Zn}>4 \mathrm{Sn}$ & $\mathrm{Zn}=8 \%$ \\
Brass/gunmetal & $2.5 \mathrm{Sn}<\mathrm{Zn}<4 \mathrm{Sn}$ & $\mathrm{Zn}=8 \%$ or $\mathrm{Sn}=3 \%$ \\
Gunmetal & $0.67 \mathrm{Sn}<\mathrm{Zn}<2.5 \mathrm{Sn}$ & $\mathrm{Sn}=3 \%$ \\
Bronze/gunmetal & $0.33 \mathrm{Sn}<\mathrm{Zn}<0.67 \mathrm{Sn}$ & $\mathrm{Sn}=3 \%$ \\
Bronze & $\mathrm{Sn}=3 \mathrm{Zn}$ & $\mathrm{Sn}=3 \%$ \\
Copper & & $\mathrm{Zn}<3 \%$ and $\mathrm{Sn}<3 \%$ \\
Copper/brass & & $3 \%=\mathrm{Zn}<8 \%$ and $\mathrm{Sn}<3 \%$ \\
Leaded alloys & & $\mathrm{Pb}>8 \%$ \\
(Leaded) alloys & & $8 \%=\mathrm{Pb}=4 \%$ \\
\hline
\end{tabular}

has more than $4 \%$ but less than $8 \%$ lead, it would be a '(leaded) brass': if the lead content is greater than $8 \%$, it is then a 'leaded brass'. Other classification schemes, if not identical, are very similar.

We have taken a completely different approach to categorising the alloy type, which is indicative of a fundamentally different philosophical approach to understanding the life histories of the objects analysed. Previous classifications have assumed that alloy composition is mostly deliberate and targeted at producing alloys with approximately modern specifications. For example, an object is only called a 'brass' if it contains more than $8 \%$ zinc or a 'bronze' if it has greater than $3 \%$ tin-in other words, if the level of the alloying element exceeds a value that is considered to have an effect on the physical properties of the object and could therefore be expected to be a conscious addition. Our approach is radically different, in that we do not want to impose any assumptions about past practice, which may have ranged from 'designed recipe' to 'randomness' caused by cycles of recycling and mixing. We wish to categorise the chemical results impartially, with the view that the concentration of particular alloying elements in a specific object depends on the life history of the object. By looking at assemblages of objects as snapshots of the overall metal flow, we aim to infer the metallurgical and social processes at work. We acknowledge that some objects will always have been made from 'primary' metal, with 'deliberate' levels of alloying, but note that such objects are easily recognised in our scheme, as shown below.

We have considered the presence of tin, lead and zinc as significant if they are above a cut-off value, which is set at $1 \%$-much lower than previous studies but high enough to exclude natural contributions from the copper ore itself. Our classification system is shown in Table 2, and is intended to have the effect of allowing the visibility of the mixed nature of copper alloys (i.e. the simultaneous presence of several alloying elements at levels below those that could be regarded as having a significant effect), rather than focusing on those objects that might have 'designed' compositions. It does mean, however, that when we refer, for example, to an alloy as being leaded brass, it may contain as little as $=1 \%$ of both zinc and lead, and it therefore would not be a brass alloy in any modern sense. 
Table 2. Copper alloy classifications used in this paper.

\begin{tabular}{lll}
\hline Symbol & Name & Definition \\
\hline C & Copper & $\mathrm{Pb}, \mathrm{Sn}, \mathrm{Zn}$ each $<1 \%$ \\
LC & Leaded copper & $\mathrm{Pb}>1 \%$; $\mathrm{Sn}, \mathrm{Zn}$ both $<1 \%$ \\
B & Bronze & $\mathrm{Sn}>1 \% ; \mathrm{Pb}, \mathrm{Zn}$ both $<1 \%$ \\
LB & Leaded bronze & $\mathrm{Sn}, \mathrm{Pb}$ both $>1 \% ; \mathrm{Zn}<1 \%$ \\
BR & Brass & $\mathrm{Zn}>1 \% ; \mathrm{Sn}, \mathrm{Pb}$ both $<1 \%$ \\
LBR & Leaded brass & $\mathrm{Zn}, \mathrm{Pb}$ both $>1 \% ; \mathrm{Sn}<1 \%$ \\
G & Gunmetal & $\mathrm{Zn}, \mathrm{Sn}$ both $>1 \% ; \mathrm{Pb}<1 \%$ \\
LG & Leaded gunmetal & $\mathrm{Zn}, \mathrm{Sn}, \mathrm{Pb}$ all $>1 \%$ \\
\hline
\end{tabular}

\section{Change of alloy composition over time}

Table 3 shows the ubiquity (percentage of the assemblage composed of that particular alloy) of each alloy type for all of the assembled data. The definitions of alloy type are based on the presence of each alloying element above $1 \%$, as listed in Table 2 . The chronological classifications used are those given in the original publications, but for Bayley and Butcher's Roman brooch data we have attempted to allocate the types to a more specific chronological phase, as described in the online supplementary material.

A number of features stand out from Table 3, most strikingly at the end of the Iron Age and at the end of the Roman period into the early Saxon. The Early Iron Age and Iron Age data of Dungworth show that the metal in circulation consists primarily of bronze, at about $73 \%$ ubiquity. Brass is almost completely absent, as is any ternary alloy containing zinc i.e. leaded brass, gunmetal and leaded gunmetal. Dungworth's Late Iron Age data shows a marked shift to a more 'Roman' pattern-characterised by the presence of brass and some of the ternary and quaternary alloys containing zinc (leaded brass, gunmetal and leaded gunmetal). Bayley and Butcher's Late Iron Age samples (of which there are only 10), are somewhat different, in that they consist primarily of bronze, with no brass, but with a combined $40 \%$ of gunmetal and leaded gunmetal, indicating that alloys containing zinc were available at this time. The early Saxon period (Blades's) material is very similar to that of the C4AD (fourth century AD Roman, Dungworth), but there is a complete change in the metal supply during the middle Saxon period (Blades's data), as indicated by a rapid drop in the ubiquity of leaded gunmetal (from 75-25\%), a rise in leaded bronze (from $18-42 \%$ ) and the re-appearance of brass and leaded brass (up to $9 \%$ and $7 \%$ respectively).

In order to investigate diachronic changes more carefully, we have created a 'time series' of alloy types by combining the data into the following sequence using the chronological intervals defined in Table 4. Some of the trends identified above are now more clearly seen by plotting the ubiquity of a single alloy category over time (Figure 1a-e). Figure 1a shows that bronze was the dominant alloy in the Iron Age, accounting for more than $70 \%$ of the objects in the assemblages, the remainder being mostly leaded bronze. Bronze declined sharply in the first century AD, with brass (Figure 1b) suddenly appearing in $30 \%$ of the objects from the late Iron Age and first century $\mathrm{AD}(\mathrm{C} 1 \mathrm{AD})$. This too declined in the

(C) Antiquity Publications Ltd, 2015 
Table 3. Ubiquity of copper alloy types in the three datasets by date; data recalculated from Blades (1995), Dungworth (1995) and Bayley \& Butcher (2004).

\begin{tabular}{|c|c|c|c|c|c|c|c|c|c|}
\hline & Copper & Leaded copper & Bronze & Leaded bronze & Brass & Leaded brass & Gunmetal & Leaded gunmetal & Total \\
\hline Bayley \& Butcher Late Iron Age & 0 & 0 & 50 & 10 & 0 & 0 & 30 & 10 & 10 \\
\hline Bayley \& Butcher AD 1-70 & 0 & 0.3 & 4.6 & 22.3 & 19.3 & 1.1 & 34.8 & 17.7 & 368 \\
\hline Bayley \& Butcher AD 43-70 & 0 & 0 & 2.2 & 7.7 & 27.5 & & 42.9 & 19.8 & 91 \\
\hline Bayley \& Butcher AD 70-170 & 0.3 & 0 & 3 & 49 & 0.7 & 0.7 & 11.1 & 35.1 & 296 \\
\hline Dungworth Early Iron Age & 0 & 0 & 72.9 & 27.1 & 0 & 0 & 0 & 0 & 59 \\
\hline Dungworth Iron Age & 0 & 0 & 73.2 & 21.4 & 1.8 & 0 & 1.8 & 1.8 & 56 \\
\hline Dungworth Late Iron Age & 2.8 & 0 & 27.8 & 11.1 & 27.8 & 0 & 19.4 & 11.1 & 36 \\
\hline Dungworth first century AD & 3.3 & 0 & 14 & 14 & 30.5 & 1.2 & 20.6 & 16.5 & 243 \\
\hline Dungworth second century AD & 1.2 & 0 & 18 & 18.4 & 13.1 & 0.4 & 24.6 & 24.2 & 244 \\
\hline Dungworth third century AD & 0.7 & 0 & 15 & 22.4 & 4.8 & 0 & 16.3 & 40.8 & 147 \\
\hline Dungworth fourth century AD & 0 & 0 & 11.5 & 24.4 & 1.3 & 0 & 12.8 & 50 & 78 \\
\hline Dungworth EROM & 0 & 0 & 16.4 & 20.1 & 4.5 & 1.5 & 23.9 & 33.6 & 134 \\
\hline Dungworth MROM & 0 & 0 & 12.5 & 21.9 & 6.3 & 3.1 & 3.1 & 53.1 & 32 \\
\hline Dungworth LROM & 1.7 & 1.1 & 13.2 & 28.7 & 2.3 & 3.4 & 13.2 & 36.2 & 174 \\
\hline Dungworth ROMN & 0.4 & 0 & 13.6 & 23.4 & 6.4 & 1.7 & 11.1 & 43.4 & 235 \\
\hline Blades Roman & 1.1 & 1.1 & 6.4 & 33 & 6.4 & 3.2 & 9.6 & 39.4 & 94 \\
\hline Blades Early Saxon & 0.3 & 0 & 2.4 & 18.3 & 0.8 & 0.5 & 2.9 & 74.8 & 377 \\
\hline Blades Middle Saxon & 4 & 0 & 8.1 & 41.6 & 9.4 & 6.7 & 5.4 & 24.8 & 149 \\
\hline Blades Late Saxon & 4.1 & 1.4 & 6.8 & 47.9 & 6.8 & 12.3 & 2.7 & 17.8 & 73 \\
\hline Caple Roman & 8.3 & 0 & 1.4 & 15.3 & 8.3 & 1.4 & 26.4 & 38.9 & 72 \\
\hline Caple Saxon & 0 & 3.8 & 3.8 & 28.8 & 5.8 & 19.2 & 9.6 & 28.8 & 52 \\
\hline Colour Key: & $10-20 \%$ & $20-40 \%$ & $>40 \%$ & & & & & & \\
\hline
\end{tabular}


Table 4. Chronological intervals and date ranges used.

\begin{tabular}{ll}
\hline Interval & Date range \\
\hline Late Bronze Age/Early Iron Age & $\begin{array}{l}\text { As Bayley \& Butcher } \\
\text { Es Bayley \& Butcher } \\
\text { Early Iron Age }\end{array}$ \\
Iron Age & As Bayley \& Butcher \\
Late (Roman) Iron Age & As Bayley \& Butcher \\
First century AD & Roman, post AD 42 \\
Second century AD & Roman \\
Third century. AD & Roman \\
Fourth century AD & Roman \\
Early Roman & First-second century AD \\
Middle Roman & Second-third century AD \\
Late Roman & Third-fourth century AD \\
Roman & First-fourth century AD \\
Early Saxon & AD 430-650 \\
Mid Saxon & AD 650-850 \\
Late Saxon & AD 850-1066 \\
Early medieval & Eleventh-thirteenth century \\
Late medieval & Thirteenth-fifteenth century \\
Post-medieval & Post-AD 1600 \\
\hline
\end{tabular}

second century $\mathrm{AD}$ and was reduced to virtually nothing by the early Saxon period. Leaded bronze (Figure 1c) dominated the Early Iron Age, and was always a significant component of the assemblage; yet, apart from a 'spike' in the post-conquest Roman brooches, it did not dominate again until the middle and late Saxon periods. The ternary copper-tin-zinc alloy $(\mathrm{Cu}-\mathrm{Sn}-\mathrm{Zn})$ gunmetal (Figure 1d) also first appeared at the Late Iron Age and Roman margin (first century AD), as did leaded gunmetal (Figure 1e) but less significantly. Leaded gunmetal, then, shows a steady increase in ubiquity from the late Iron Age through the Roman period, peaking at over $70 \%$ in the early Saxon period, whereas gunmetal peaked during the first century AD and declined for the rest of the millennium.

Some of the irregularity of the profiles shown in Figure 1 may well be due to overlap and uncertainty between the chronological phases; another factor may be that the four sources in the sample contain objects of different function and technology from different regions of Britain. Smythe (1931-1937), for example, in his study of 250 metallographic sections of Roman copper alloy objects from northern Britain, concluded that $61 \%$ had been cast and $39 \%$ wrought. We take some comfort from the analysis shown in Table S4 (supplementary material), which shows our alloy reclassification of the Roman objects from each published source, indicating that the ubiquity of each alloy type is approximately consistent across the data. The trends in Figure 1 become even clearer if we restrict the data to the better dated material through the Roman period (i.e. using Dungworth's categories of C1AD$\mathrm{C} 4 \mathrm{AD}$, and dropping his less chronologically precise EROM, MROM and LROM, as well as the Bayley \& Butcher Roman brooches and Blades's Roman group), as shown in Figure 2 (containing 1486 samples). This reveals a monotonic decline in the ubiquity of brass from

(C) Antiquity Publications Ltd, 2015 

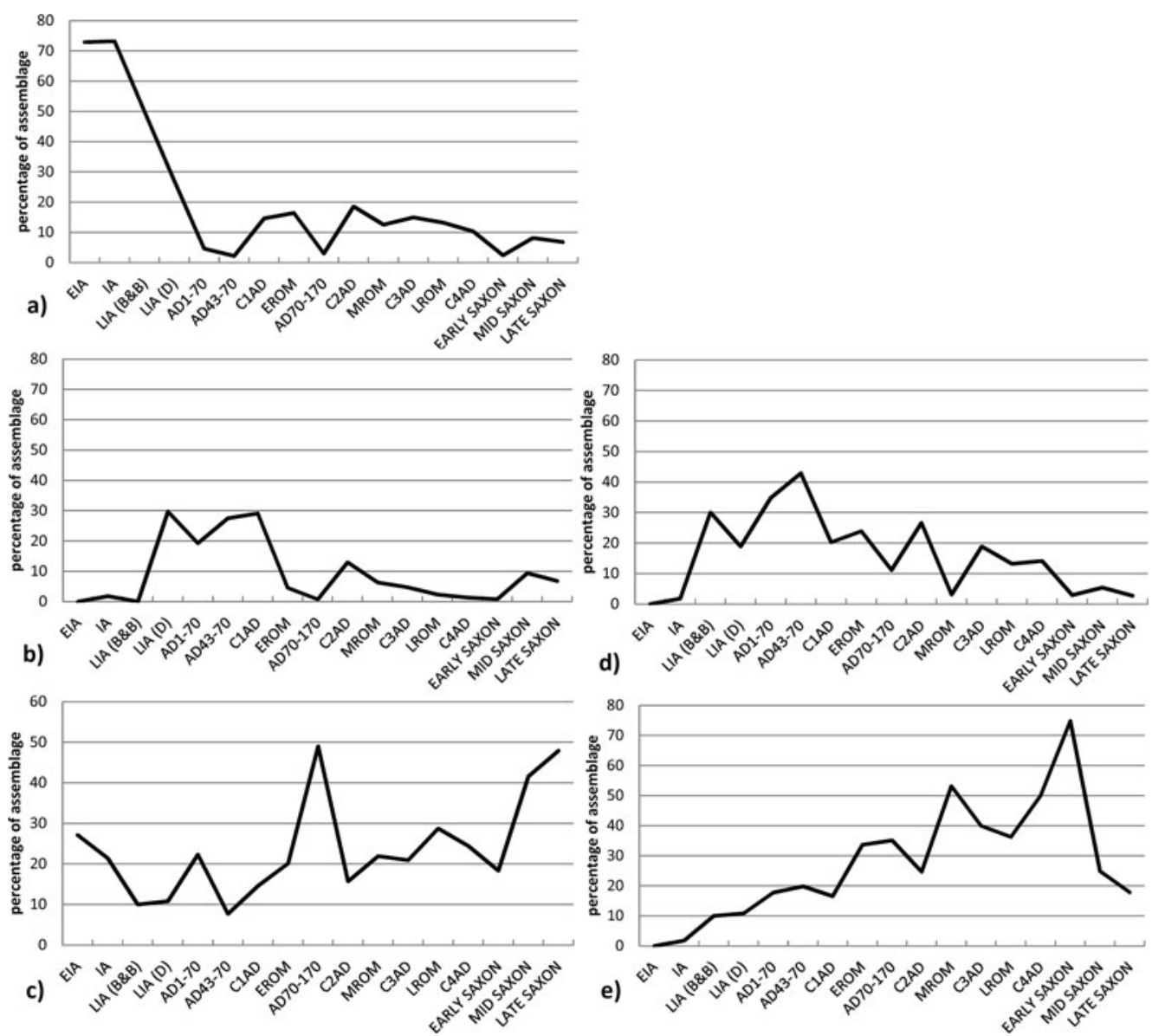

Figure 1. Ubiquity of specific alloy types over time: a) bronze; b) brass; c) leaded bronze; d) gunmetal; e) leaded gunmetal. Data recalculated from Blades (1995), Dungworth (1995) and Bayley \& Butcher (2004).

the first century $\mathrm{AD}$, accompanied by a strong and monotonic increase in the ubiquity of leaded gunmetal, peaking significantly in the early Saxon period and followed by a rapid fall. Gunmetal peaked in the second century AD, after the decline of brass had begun, but then dropped away in parallel to the decrease in brass. We interpret the brass signal as the injection of new metal stock (in the form of brass) in or just before the first century AD. The peak in the abundance of the ternary alloy gunmetal $(\mathrm{Cu}-\mathrm{Zn}-\mathrm{Sn})$ in the second century $\mathrm{AD}$ we take to indicate the subsequent practice of mixing this new brass with the local bronze, as previously suggested by Dungworth (1997). We also take the relentless rise in the presence of the quaternary alloy leaded gunmetal as a clear indication of the increasingly widespread practice of mixing and recycling metal in general, given that the most likely route to the production of gunmetal and leaded gunmetal is the mixing of copper alloys containing both tin (bronze or leaded bronze) and zinc (primarily brass). We contend, therefore, that the recycling of metal (conservatively indicated by the ubiquity of leaded gunmetal) was a 


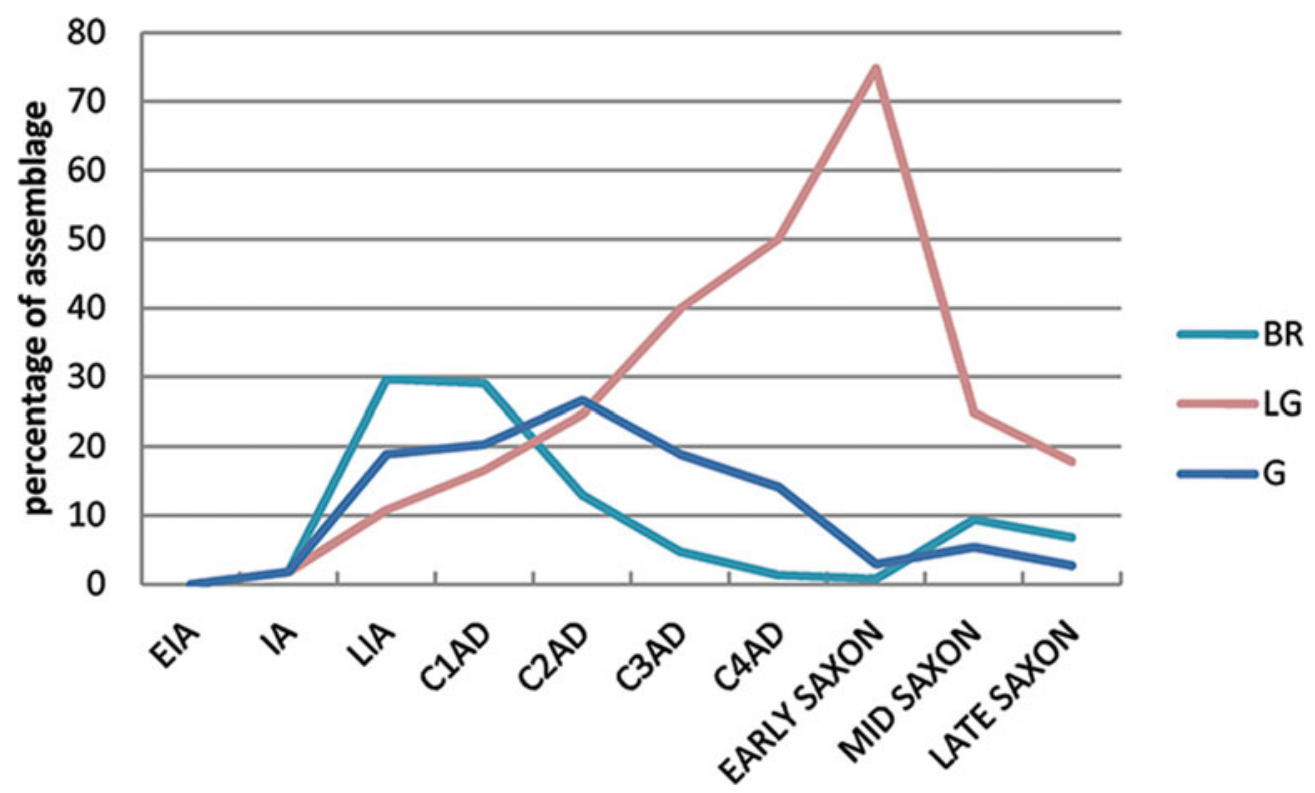

Figure 2. Ubiquity of brass, gunmetal and leaded gunmetal over time, using only data from Blades (1995) and Dungworth (1995), with well-defined chronological groupings.

practice that steadily increased throughout the Roman occupation of Britain and continued, using the same metal stock, into Blades's early Saxon phase (AD 430-650), as evidenced by the peak in the ubiquity of leaded gunmetal at this time. By our interpretation, at least $70 \%$ of the copper alloy objects in circulation contained some proportion of recycled metal. Whether this indicates only the recycling of Roman metal in the early Saxon period, or a continuing flow of fresh metal that was rapidly mixed with recycled stock, is more difficult to say, and is discussed further below. It has long been recognised that the curation and recycling of Roman metalwork, both ferrous and non-ferrous, took place in the fifth and sixth centuries (e.g. Fleming 2012), but this is the first time that we have had any clear indication of the scale at which such recycling may have taken place.

It is possible to combine the data shown in Figure 2 to emphasise the significance of all alloy types containing zinc during the Roman and early Saxon periods. This is done by combining the ubiquities of brass+leaded brass+gunmetal+leaded gunmetal into a 'zinc' group, and copper+leaded copper+bronze+leaded bronze into a 'no zinc' group, as shown in Figure 3. This emphasises the importance and prevalence of alloys containing zinc throughout the Roman period and continuing into the early Saxon period, but it is not a direct measure of the amount of zinc in circulation, for using our definitions any alloy with $>1 \%$ zinc would be counted as a zinc-containing alloy. Figure 4 shows the actual distribution of the zinc content in Roman brass, Roman gunmetal and Roman leaded gunmetal, compared to early Saxon leaded gunmetal. This shows that brass (i.e. using our definition, a copper-zinc alloy, with tin and lead $<1 \%$ ) was remarkably consistent in terms of zinc content throughout the whole Roman period (although of course the majority of (C) Antiquity Publications Ltd, 2015 


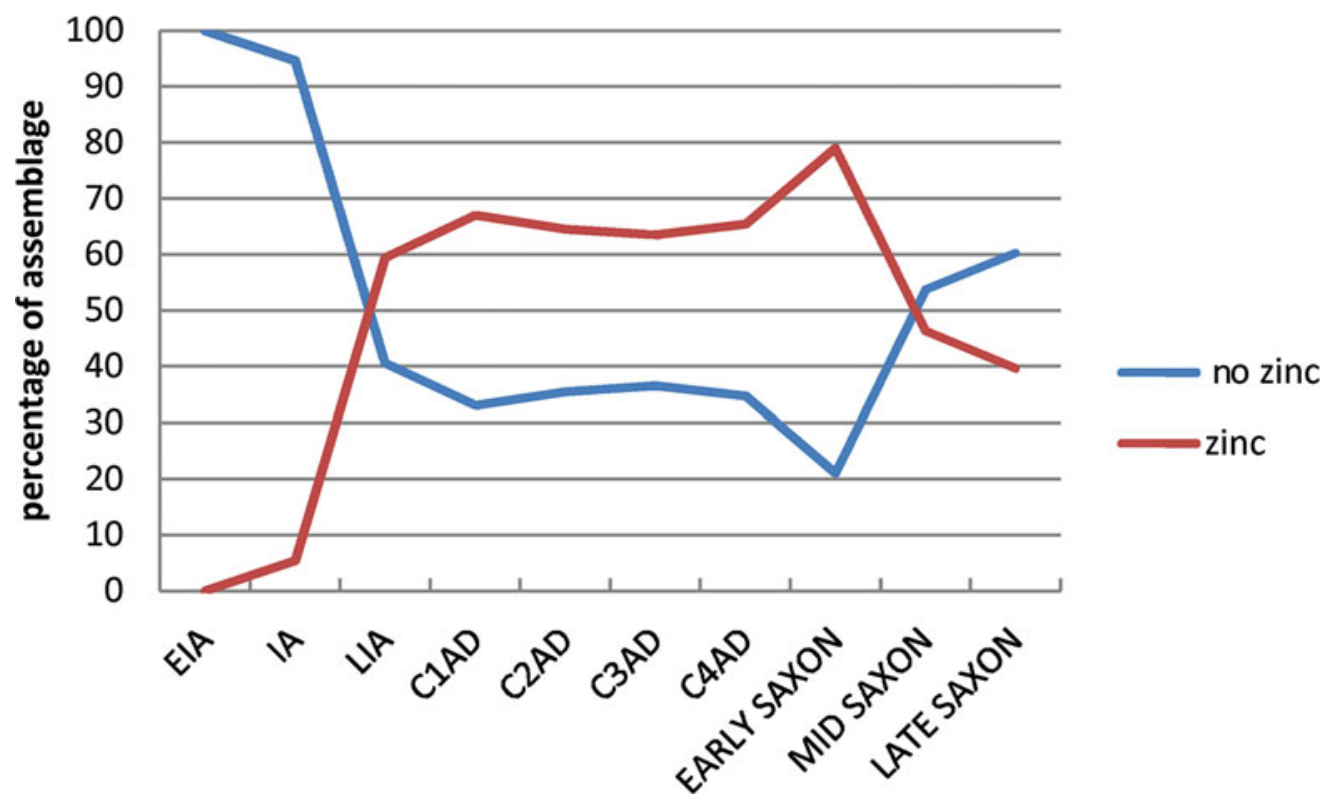

Figure 3. Ubiquity over time of alloys containing zinc compared with those containing no zinc; data recalculated from Blades (1995) and Dungworth (1995).

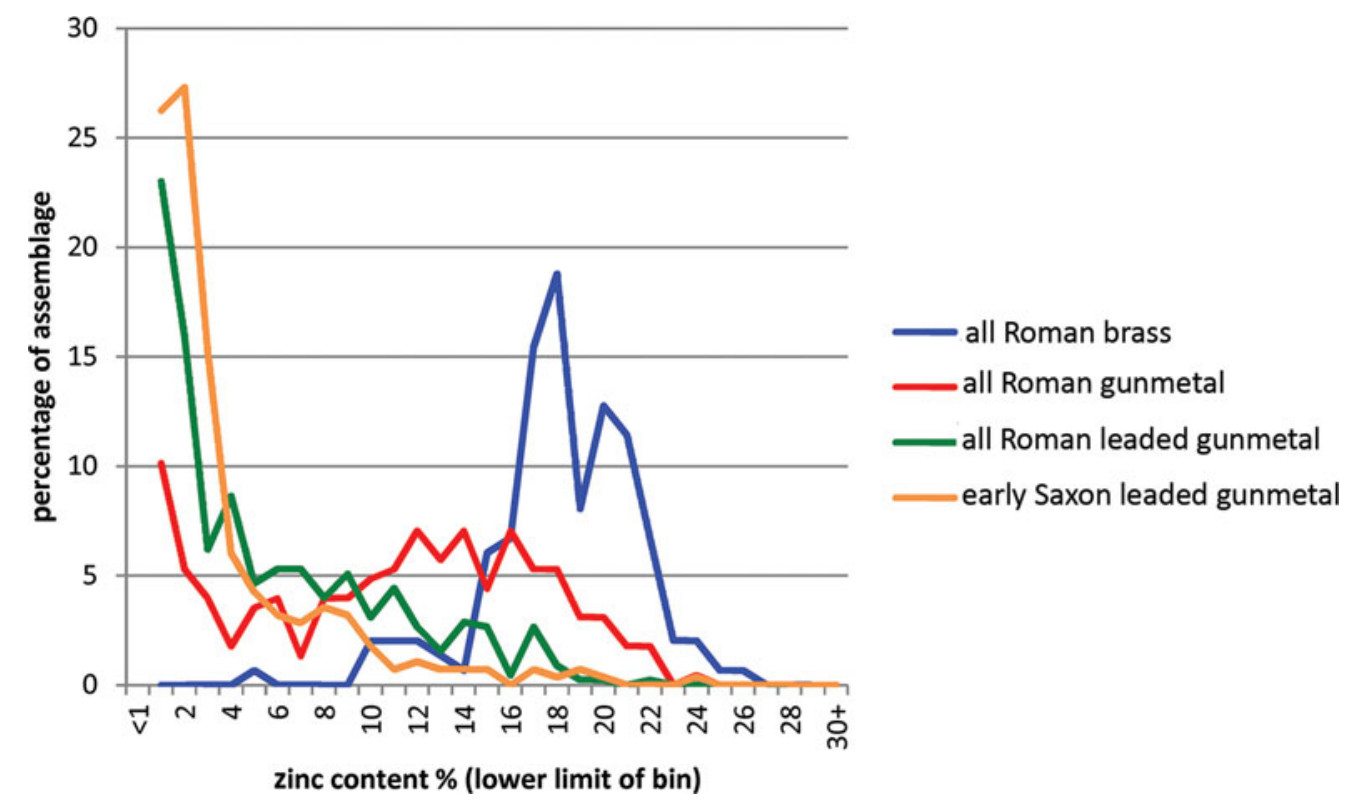

Figure 4. Distribution of zinc in Roman and early Saxon zinc-containing alloys; data recalculated from Blades (1995) and Dungworth (1995). 
the brass objects belong to the first century AD), with a typical zinc content of 15-22\%. The zinc distribution in Roman gunmetal $(\mathrm{Cu}-\mathrm{Zn}-\mathrm{Sn})$ shifted to a broader and lower peak between about 10 and $20 \%$ zinc, with a few samples having $<5 \%$ zinc. This is consistent with the idea that this alloy was made by mixing brass with bronze, with the consequence that the zinc levels were diluted. Roman leaded gunmetal $(\mathrm{Cu}-\mathrm{Zn}-\mathrm{Sn}-\mathrm{Pb})$, on the other hand, has a very different pattern, with the majority of samples having $<5 \%$ zinc, and a 'tail' in the zinc distribution going up to $c .12 \%$. The early Saxon pattern for zinc in leaded gunmetal is virtually identical to this, and, as shown in Table 3, the early Saxon period was dominated by this alloy type (c. 75\%), and the almost complete absence of any other alloy containing zinc. We are led to conclude not only that the dominant presence of leaded gunmetal is indicative of the use of highly recycled metal stock, but also that the nature of such metal in the early Saxon period is indicative of a large-scale continuity of Roman metal in circulation.

It has long been known that the zinc content of Roman copper alloys declined after the first century AD. For example, from the analysis of Roman brass coins, Caley (1964) noticed that the zinc content declined from the late first century $\mathrm{BC}$ to the early third century $\mathrm{AD}$ (when production of brass coins ceased). He suggested that brass production started in the late first century BC but stopped shortly after, and that brass coins of the late first century AD onwards were made from recycled brass. This 'zinc decline' (Dungworth 1995: 148; 1997: 907) was thought to be a consequence of the volatility of zinc, which meant that the zinc content of the brass declined after each re-melting (Caley 1964: 99). Figure 4 shows a somewhat more complex picture. The zinc content of brass (copper with zinc $=1 \%$ ) seems to be constant at $15-22 \%$ throughout the Roman period in Britain, although the ubiquity of such alloys was very low after the second century. This suggests that the brass that has survived is largely primary metal. The 'zinc decline' was due to the increasing ubiquity of other zinc-containing alloys (gunmetal and leaded gunmetal), with a significantly lower zinc content. Although the loss of zinc through volatilisation is undoubtedly a factor to be considered, we suggest that the primary cause of Caley's 'zinc decline' was most likely the mixing of brass with other alloy types.

\section{Trace elements: allocation of an object to a 'copper category'}

The picture of recycling suggested by our analysis of the main copper alloy types is further supported by analysis of the trace elements in the copper objects. We have described elsewhere the philosophy behind our approach to classifying copper alloy objects into one of 16 'copper categories' using the presence or absence of four key trace elements in the copper itself-arsenic, antimony, gold and nickel (Bray \& Pollard 2012; Pollard \& Bray 2014). There are two stages to our interpretation, the first of which is a broad categorisation step, based upon the presence or absence of these four diagnostic elements. The second considers the distribution of the elements within and between the copper categories. For example, whether the arsenic is broadly distributed or heavily skewed, mono- or multi-modal and so on, can be associated with metallurgical practice. It is important to appreciate immediately that 'copper category' is not synonymous with 'copper source'- several sources (mines) may have produced the same 'category' of copper, and a single source may have produced (C) Antiquity Publications Ltd, 2015 
more than one copper type, depending on ore geochemistry, ore pre-treatment, smelting conditions, refining processes and so on. Our system is intended to look at the complete biography of the metal that composes the objects, rather than focus simply on the 'birth' of the metal. In other words, we see a separation between the unit of metal that makes up an object (which may persist in broad association for centuries), and the form of the object itself (which could be a relatively short event before re-casting).

To allocate an object to category, we first mathematically strip out the alloying elements (tin, lead and zinc), and re-normalise the remaining elements to $100 \%$, to give what we describe as the composition of the 'copper base'. We realise that this is somewhat artificial, but it is a necessary step to avoid 'dilution effects' on the trace elements when significant levels of alloying elements have been added. It also assumes that the trace elements of interest are primarily associated with the copper rather than the alloying elements. This is reasonable in the case of antimony and nickel, but more difficult with gold (which is often associated with lead), and perhaps a matter of definition with arsenic. We deal with the lead/gold issue by checking that objects in the 'Ag present' categories do not all contain high lead in the data under study. With regard to arsenic (and possibly also antimony), we can broadly check that it is an incidental component of the copper alloy (and therefore associated with the copper) through the overall arsenic distribution pattern. In cases where it is a deliberate alloying element, we see dramatic peaks at high percentages in the distribution plots, which are different to the gradually declining curves at low abundance that are associated with incidental presence. At the levels encountered here, we can, however, safely ignore this issue.

Having calculated a 'raw copper composition' for each object, we can now assign each object to a 'copper category' (CC) based on the presence or absence of the four trace elements arsenic, antimony, gold and nickel. We simply allocate the metal composition to one of 16 bins (denoted as copper category 1-16), based on the presence or absence $(\mathrm{Y} / \mathrm{N})$ of each trace element, and ordered as listed in Table 5. Thus, a metal with arsenic but nothing else would be YNNN (assigned as Group 2 in our numbering system), whereas 'Ag-only' would be NNYN (Group 4). Again, an arbitrary decision is needed about when 'presence' becomes 'absence'. This can be determined by a close examination of the data to estimate minimum detectable levels $(\mathrm{mdl})$ for each element, but in mixed data (i.e. data from different methods of analysis and different dates of determination) it is often only possible to use an arbitrary cut-off, which, as in the work reported here, we typically set at $0.1 \%$. It is possible to check the sensitivity of the outcomes to this arbitrary choice by varying the cut-off value and looking for patterns of stability in the distributions of copper categories. For a more complete analysis, we would then continue by using mapping options within a GIS to determine the extent, movement and timing of the circulation of particular copper categories.

It is important to note that this method can be applied independently, without any prior knowledge of copper sources, and is thus a powerful means of testing previous assumptions. While there is undoubtedly information about source within these descriptions, we do not make any assumptions about allocating a particular copper category to a specific copper source, known or unknown. A single category may contain copper from one or more discrete geological sources-all we can say is that these sources must have the same characteristic pattern of trace elements. For example, the As-Sb-Ag metal of Group 12 
Table 5. Copper categories used in this study, classified by presence/ absence of non-alloy trace elements, in the order arsenic (As), antimony $(\mathrm{Sb})$, silver $(\mathrm{Ag})$ and nickel $(\mathrm{Ni})$.

\begin{tabular}{ccccc}
\hline Copper Category & As & Sb & Ag & Ni \\
\hline 1 & & & & \\
2 & $\mathrm{~N}$ & $\mathrm{~N}$ & $\mathrm{~N}$ & $\mathrm{~N}$ \\
3 & $\mathrm{Y}$ & $\mathrm{N}$ & $\mathrm{N}$ & $\mathrm{N}$ \\
4 & $\mathrm{~N}$ & $\mathrm{Y}$ & $\mathrm{N}$ & $\mathrm{N}$ \\
5 & $\mathrm{~N}$ & $\mathrm{~N}$ & $\mathrm{Y}$ & $\mathrm{N}$ \\
6 & $\mathrm{~N}$ & $\mathrm{~N}$ & $\mathrm{~N}$ & $\mathrm{Y}$ \\
7 & $\mathrm{Y}$ & $\mathrm{Y}$ & $\mathrm{N}$ & $\mathrm{N}$ \\
8 & $\mathrm{~N}$ & $\mathrm{Y}$ & $\mathrm{Y}$ & $\mathrm{N}$ \\
9 & $\mathrm{~N}$ & $\mathrm{~N}$ & $\mathrm{Y}$ & $\mathrm{Y}$ \\
10 & $\mathrm{Y}$ & $\mathrm{N}$ & $\mathrm{Y}$ & $\mathrm{N}$ \\
11 & $\mathrm{~N}$ & $\mathrm{Y}$ & $\mathrm{N}$ & $\mathrm{Y}$ \\
12 & $\mathrm{Y}$ & $\mathrm{N}$ & $\mathrm{N}$ & $\mathrm{Y}$ \\
13 & $\mathrm{Y}$ & $\mathrm{Y}$ & $\mathrm{Y}$ & $\mathrm{N}$ \\
14 & $\mathrm{~N}$ & $\mathrm{Y}$ & $\mathrm{Y}$ & $\mathrm{Y}$ \\
15 & $\mathrm{Y}$ & $\mathrm{Y}$ & $\mathrm{N}$ & $\mathrm{Y}$ \\
16 & $\mathrm{Y}$ & $\mathrm{N}$ & $\mathrm{Y}$ & $\mathrm{Y}$ \\
& $\mathrm{Y}$ & $\mathrm{Y}$ & $\mathrm{Y}$ & $\mathrm{Y}$ \\
\hline
\end{tabular}

(YYYN) is associated with Bronze Age mines in Ross Island of County Kerry, Ireland, but also with the 'Ösenring' metal type from continental Europe. Mapping and chronology can, however, help to distinguish the metal in circulation from geographically discrete sources.

\section{Change of copper categories over time}

We have, as yet, only been able to apply our methodology for trace elements to the data published by Blades (1995), as none of the other studies (Caple 1986; Dungworth 1995; Bayley \& Butcher 2004) reported the full suite of trace elements. This means that in the Roman period we are currently restricted to the 94 samples analysed by Blades and simply identified chronologically as 'Roman'. It does, however, allow us to look at the continuity of copper supply from the end of the Roman period into the medieval era. Table 6 shows the allocation of all of Blades's data into copper category by period.

The Roman copper objects are all made of copper categories containing no nickel, and only CC6, a mere $1.1 \%$ of the assemblage, contains arsenic. The Roman assemblage is dominated by copper of CC3 (NYNN, or copper which contains only antimony as an impurity above $0.1 \%$ ), with a contribution from CC7 (NYYN, copper with antimony and gold). Our work with Bronze Age copper (Bray 2009; Bray \& Pollard 2012) suggests that in Britain this combination of copper types, both containing antimony, is uniquely Roman, and as yet we do not know where it came from, or whether it represents partially refined copper containing both arsenic and antimony, from which the arsenic has been removed. This seems a plausible scenario due to the higher vulnerability of arsenic to loss through simple oxygen refining (Bray \& Pollard 2012). Copper categories CC9-16, which contain (C) Antiquity Publications Ltd, 2015 
Table 6. Percentages of artefacts of a particular period in each copper category; data recalculated from Blades (1995).

$\begin{array}{lllllllllllllllllll}\mathrm{CC} 1 & \mathrm{CC} 2 & \mathrm{CC} 3 & \mathrm{CC} 4 & \mathrm{CC} 5 & \mathrm{CC} 6 & \mathrm{CC} 7 & \mathrm{CC} 8 & \mathrm{CC} 9 & \mathrm{CC} 10 & \mathrm{CC} 11 & \mathrm{CC} 12 & \mathrm{CC} 13 & \mathrm{CC} 14 & \mathrm{CC} 15 & \mathrm{CC} 16\end{array}$

\begin{tabular}{|c|c|c|c|c|c|c|c|c|c|c|c|c|c|c|c|c|}
\hline Roman & 12.8 & 0.0 & 62.8 & 4.3 & 0.0 & 1.1 & 19.1 & 0.0 & 0.0 & 0.0 & 0.0 & 0.0 & 0.0 & 0.0 & 0.0 & 0.0 \\
\hline Early Saxon & 3.7 & 0.3 & 28.9 & 5.0 & 0.3 & 2.1 & 48.3 & 0.0 & 0.5 & 1.1 & 1.3 & 4.0 & 0.5 & 1.6 & 0.3 & 2.1 \\
\hline Middle Saxon & 8.7 & 8.7 & 14.1 & 2.0 & 2.7 & 7.4 & 34.2 & 0.7 & 2.0 & 0.0 & 1.3 & 14.1 & 0.0 & 1.3 & 0.7 & 2.0 \\
\hline Late Saxon & 13.7 & 2.7 & 41.1 & 5.5 & 0.0 & 5.5 & 17.8 & 0.0 & 0.0 & 0.0 & 0.0 & 11.0 & 0.0 & 0.0 & 0.0 & 2.7 \\
\hline Early medieval & 13.8 & 1.7 & 25.9 & 1.7 & 1.7 & 27.6 & 12.1 & 0.0 & 0.0 & 0.0 & 1.7 & 5.2 & 0.0 & 0.0 & 0.0 & 8.6 \\
\hline Late medieval & 9.6 & 1.1 & 7.0 & 10.3 & 5.1 & 20.2 & 6.6 & 0.4 & 0.7 & 1.5 & 0.7 & 23.5 & 0.0 & 2.6 & 4.0 & 6.6 \\
\hline Post-medieval & 9.9 & 2.4 & 4.7 & 8.0 & 24.1 & 1.9 & 4.7 & 1.9 & 0.5 & 1.9 & 5.2 & 13.2 & 0.9 & 2.8 & 10.4 & 7.5 \\
\hline Colour key: & $>30 \%$ & $10-20 \%$ & $5-10 \%$ & & & & & & & & & & & & & \\
\hline
\end{tabular}

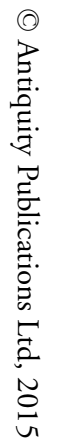

\section{Method}




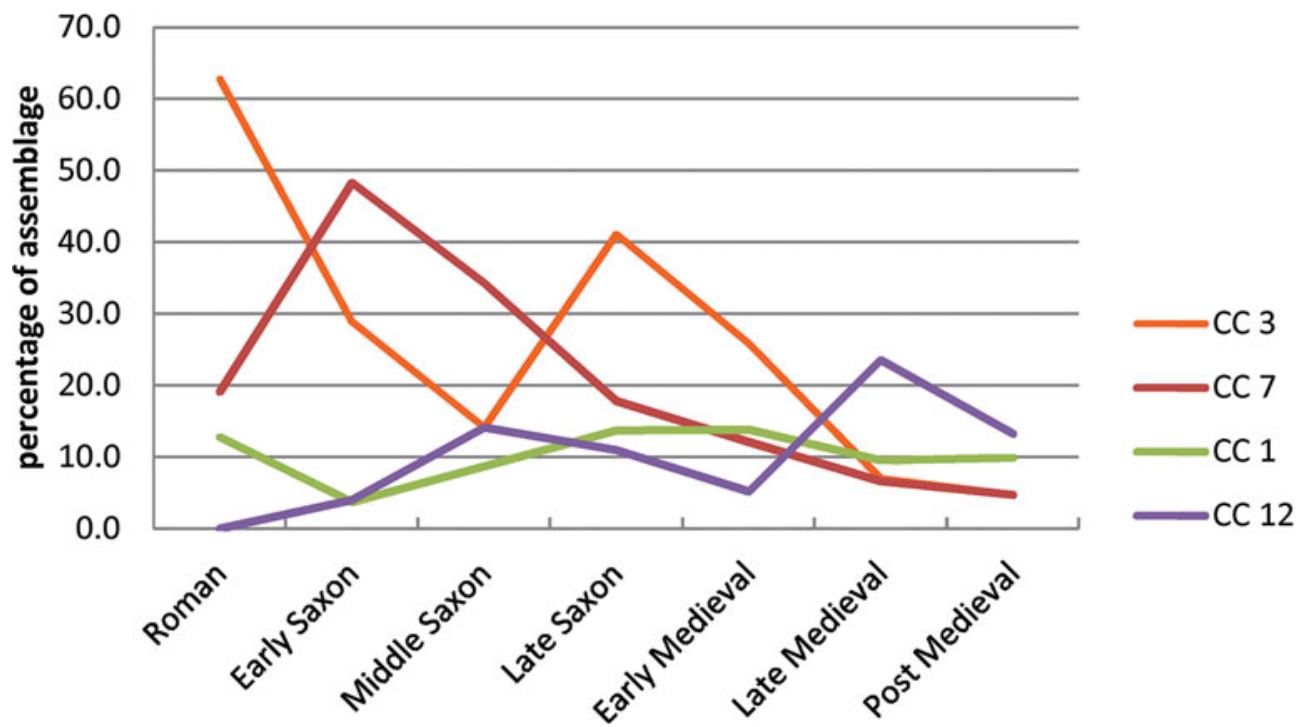

Figure 5. Ubiquity of the main copper categories (1, 3, 7 and 12) identified in Britain from the Roman period to the medieval period; data recalculated from Blades (1995).

various combinations of a wider range of trace elements than those found in Roman copper, first appeared in the early Saxon period, but all in small proportions of the assemblage.

Figure 5 shows the ubiquity of the main copper types (1,3, 7 and 12) identified in Britain from the Roman period to the medieval era. CC3 (NYNN) dominated the metal stock in the Roman period ( $>60 \%$ of the objects analysed), and declined from then until the mid-Saxon period (c. 15\%), after which it experienced a revival in the late Saxon period (>40\%). CC7 (NYYN) rose from 20\% of the assemblage in the Roman period to nearly $50 \%$ in the early Saxon period, and then declined. CC12 (YYYN) was absent in the Roman period, but rose to $c$. $15 \%$ of the metal stock by the mid-Saxon period. CC1 (NNNN, a copper base containing no other trace elements) was generally between 5 and $15 \%$ of the assemblage throughout the entire sequence. Overall, we see the continuing dominance from the Roman to the middle Saxon period of two copper categories, CC3 and CC7, which are rarely seen in any other British archaeological contexts. When combined with the overall alloying patterns discussed earlier, it seems clear that this is caused by the reuse and recycling of earlier Roman metal, and therefore also continuity in technological practice. The simplest explanation for the decline of CC3 (antimony only) in the early Saxon phase, combined with a rise in both CC7 (antimony+gold) and CC12 (arsenic, antimony and gold), is that we are seeing the arrival of new metal alongside the re-use of Roman metal, which consisted of CC12. The recycling or refining of CC12 would result in CC7, which has had the arsenic driven off, and thus metal consisting of CC3 represents predominantly recycled Roman material, whereas CC7 could represent either refined or recycled CC12. We note that if CC3 and CC7 were to be mixed, the resulting copper would still be classified as CC7.

(C) Antiquity Publications Ltd, 2015 


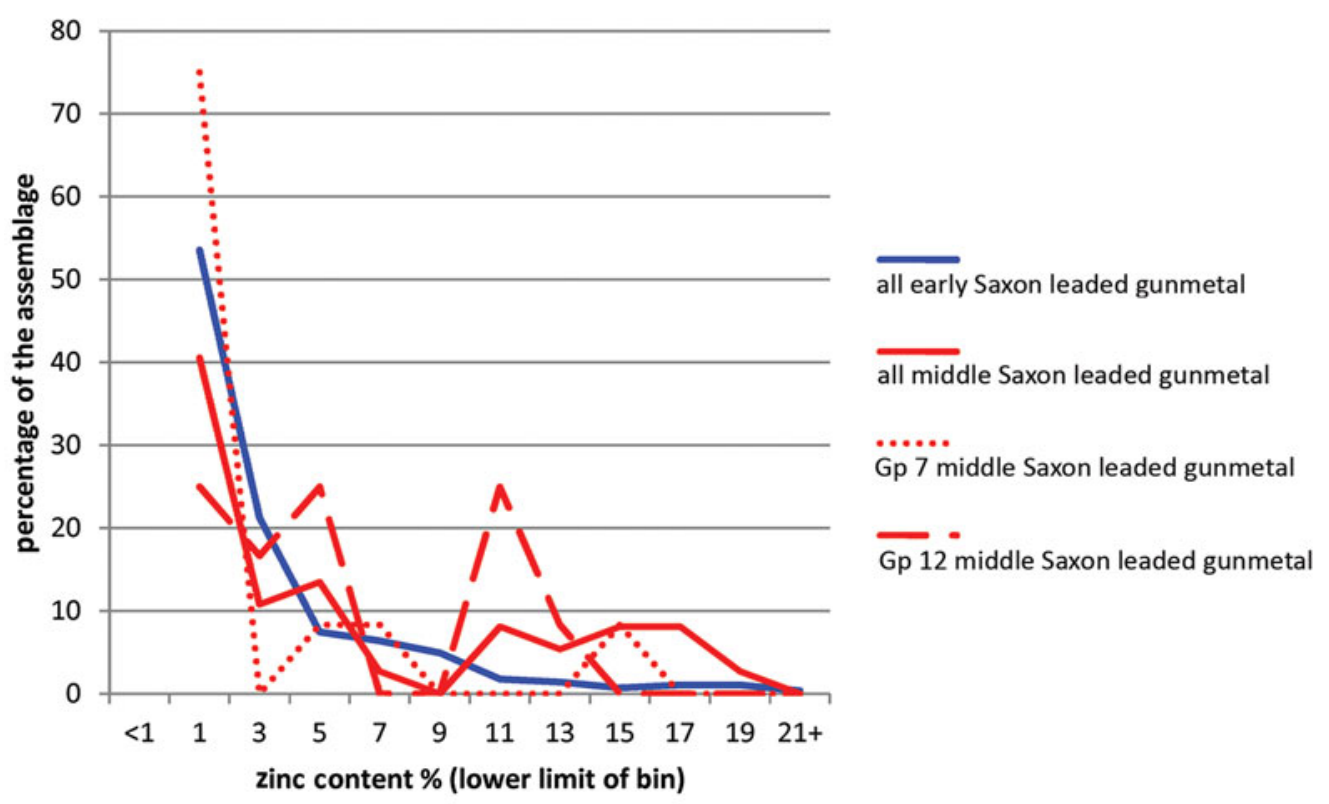

Figure 6. Comparison of zinc levels in early and middle Saxon leaded gunmetals; data recalculated from Blades (1995); middle Saxon is also divided by copper group ( 7 is associated with Roman and early Saxon signatures, 12 with fresh metal input).

The CC12 (YYYN; copper with arsenic, antimony and gold, but no nickel) that appeared in the middle Saxon period but then declined into the early medieval period is crucial to understanding the relationship between English and continental patterns of copper use. It may indicate a brief importation of large volumes of fresh, relatively unaltered copper-alloy material reaching England from continental Europe during the middle Saxon period. This supply quickly closed with the events of the late Saxon period, and this particular copper base only became prevalent again in the later medieval period. It is tempting to link the influx of a fresh metal supply in the middle Saxon period to renewed trade and cultural contacts with the Franks and, through them, the Mediterranean world. It is apparent from the commercially developed parts of eastern England during the eighth and ninth centuries, at sites such as Flixborough and Brandon, that at least some high-status communities were able to discard reusable metalwork on a lavish scale (Evans \& Loveluck 2009).

We can shed a little more light on the changes to metal supply that happened between the early and middle Saxon periods by combining information on copper category with alloy type. Focusing on zinc, Figure 6 shows the zinc distributions in all early and middle Saxon leaded gunmetals to be similar. However, if we divide the middle Saxon gunmetals into those made from CC7 copper and those from CC12, we see that although both are dominated by values $<5 \%$ zinc, a significant proportion $(>20 \%)$ of the CC12 copper samples contain around $11 \%$ zinc. We have shown above (Table 6, Figure 5) that CC12 copper (YYYN) is a new addition to the metal supply in the middle Saxon 
period. We suggest, therefore, that we are seeing an injection of fresh metal supply into Britain during the middle Saxon period, consisting of CC12 copper alloyed with c. $11 \%$ zinc.

\section{Conclusions}

All of the authors of the data that we have used accepted in their original publications that recycling was a necessary part of the picture. For example, Dungworth (1995), in the abstract of his dissertation, stated that:

It is clear that copper alloys were recycled and that some care was taken over the ways in which this occurred. The lack of low zinc brasses shows that this alloy was rarely recycled on its own. If brass was recycled then it was always mixed with some bronze. (Dungworth 1995: i).

We would argue that greater clarity can be given to this discussion by changing the way in which we define copper alloy types, using a system that moves away from an assumption that alloy design is principally deliberate to an impartial categorisation in which the concentration of particular alloying elements in a specific object depends on the life history of the object. If this is done, not only can we see that recycling was significant during and after the Roman occupation, but we can also suggest that recycling was not necessarily as well controlled as is suggested by Dungworth and others.

Under our definitions, brass in Britain was primarily an alloy of the first century AD (and the Late Iron Age), but continued in circulation in declining ubiquity (as a pure copperzinc alloy) until the start of the middle Saxon period, accompanied by increasing amounts of other zinc-containing alloys (gunmetal and leaded gunmetal), indicating that some of the brass was being mixed with bronze and leaded bronze to create these mixed alloys. We suggest that, in a system that contains zinc-bearing alloys, the proportion of leaded gunmetal (copper with more than $1 \%$ of tin, lead and zinc respectively) gives a minimum estimate for the frequency of recycled metal in circulation. Yet we do recognise that alloy design, for example the deliberate addition of lead to increase fluidity, is also a part of this story.

By combining data from various sources to give a long time-depth and a substantial number of analyses, we can see a number of major transition points in the pattern of copper alloy circulation in Britain-specifically, at the Late Iron Age/Roman transition, and, significantly, at the early to middle Saxon transition, indicating continuity from the late Roman fourth century AD into the early Saxon period. These transitions are evidenced by large changes in the patterns of alloy types represented in the assemblages, and also, where we have been able to examine it, in the categories of copper (defined by the trace elements arsenic, antimony, gold and nickel) in circulation. Taken together, these changes suggest new injections of copper into the metal supply at these times. This echoes the model of 'metal systems' proposed by Caple, in which he saw the metal in circulation as made up of the metal stock, to which is periodically added "freshly made metal [...] coming in the forms of ready formed objects and/or fresh metal to be fabricated in a variety of forms and states, to add to the existing metal stock" (Caple 1986: 530). We endorse this model, and (C) Antiquity Publications Ltd, 2015 
suggest that our combination of redefined alloy types with copper categories can help to illuminate and quantify this system with increased clarity.

We accept, of course, that this work represents merely the starting point for a much more detailed analysis of the metal circulation system. It is essential to consider the data broken down into more specific typological, technological, chronological and geographical categories. It is also necessary to combine the metallurgical data with other forms of archaeological information-to see if, for example, the appearance of CC12 copper in the middle Saxon period reflects the closer continental links that are similarly mirrored in new forms of ornamental metalwork and the reintroduction of wheel-turned pottery and silver coinage. Such work requires the careful re-analysis of more good quality analytical data.

\section{References}

BAYley, J. \& S. BuTCHER. 2004. Roman brooches in Britain: a technological and typological study based on the Richborough Collection. London: Society of Antiquaries of London.

BLADES, N.W. 1995. Copper alloys from English archaeological sites 400-1600 AD: an analytical study using ICP-AES. Unpublished PhD dissertation, University of London. Available at: http://ethos.bl.uk/OrderDetails.do?uin=uk.bl.ethos. 261778 (accessed 18 February 2015).

BRAY, P.J. 2009. Exploring the social basis of technology: re-analysing regional archaeometric studies of the first copper and tin-bronze use in Britain and Ireland. Unpublished PhD dissertation, University of Oxford.

BraY, P.J. \& A.M. POLlard. 2012. A new interpretative approach to the chemistry of copper-alloy objects: source, recycling and technology. Antiquity 86: 853-67. http://dx.doi.org/10.1017/S0003598X00047967

CALEY, E.R. 1964. Orichalcum and related ancient alloys (Numismatic Notes and Monographs 151). New York: American Numismatic Society.

CAPLE, C. 1986. An analytical appraisal of copper-alloy pin production: 400-1600 AD. Unpublished PhD dissertation, University of Bradford.
DungworTH, D.B. 1995. Iron Age and Roman copper alloys from northern Britain. Unpublished $\mathrm{PhD}$ dissertation, Durham University. Available at: http://etheses.dur.ac.uk/1024/ (accessed 21 January 2015).

- 1997. Roman copper alloys: analysis of artefacts from northern Britain. Journal of Archaeological Science 24: 901-10. http://dx.doi.org/10.1006/jasc.1996.0169

Evans, C.H. \& C. LOVELUCK. 2009. Life and economy at Early Medieval Flixborough c. AD 600-1000. The artefact evidence. Oxford: Oxbow Books.

FLEMING, R. 2012. Recycling in Britain after the fall of Rome's metal economy. Past and Present 217: 3-45. http://dx.doi.org/10.1093/pastj/gts027

Peterson, D.L. 2009. Production and social complexity. Bronze Age metalworking in the Middle Volga, in B.K. Hanks and K.M. Linduff (ed.) Social complexity in prehistoric Eurasia. Monuments, metals, and mobility: 187-214. Cambridge: Cambridge University Press.

Pollard, A.M. \& P. Bray. 2014. The archaeological bazaar: scientific methods for sale? Or: 'putting the 'arch-' back into archaeometry', in A. Wylie and R. Chapman (ed.) Material evidence: learning from archaeological practice. Abingdon \& New York: Routledge.

SMYTHE, F.A. 1931-1937. Roman objects of copper and iron from the north of England. Proceedings of the University of Durham Philosophical Society IX: 382-405.

Received: 7 January 2014; Accepted: 27 March 2014; Revised: 25 April 2014 